Journal of Finance - Marketing http://jfm.ufm.edu.vn

THE IMPACT OF TAX COMPETITION ON FOREIGN DIRECT INVESTMENT IN ASEAN COUNTRIES

Nguyen Van Thuan, Nguyen Thi Kim Chi, Tran Xuan Hang, Nguyen Minh Hang

University of Finance - Marketing

Received date: December 4, 2019 Accepted: December 18, 2019 Post date: February 25, 2021

\begin{abstract}
The paper aims to analyze the impact of tax polices, through income and consumption taxes, in the process of attracting FDI in six developing countries in ASEAN (Cambodia, Indonesia, Malaysia, Philippines, Thailand and Vietnam) in the period 2000 - 2017. By considering the impact of income tax and consumption tax, POLS, FEM, REM and GLS estimation method, empirical results show that income tax and consumption tax have a positive impact on FDI. On that basis, the study provides some tax policy recommendations to attract FDI to this group of countries.
\end{abstract}

Keywords: Tax, tax poplices, Foreign Development Investment (FDI). 
Tạp chí Nghiên cứu Tài chính - Marketing

http://jfm.ufm.edu.vn

\title{
TÁC ĐộNG CỦA CHÎNH SÁCH THUẾ ĐẾN ĐẦU TƯ TRỰC TIẾP NƯớC NGOÀI TẠI CÁC QUỐC GIA ASEAN
}

\author{
Nguyễn Văn Thuận, Nguyễn Thị Kim Chi, Trần Xuân Hằng, Nguyễn Minh Hằng \\ Truờng Đại học Tài chính - Marketing
}

Ngày nhận bài: 04/12/2019 Ngày chấp nhận đăng: 18/12/2019 Ngày đăng: 25/02/2021

Tóm tắt: Bài báo phân tích tác động của chính sách thuế, thông qua thuế thu nhập, thuế tiêu dùng và tổng số thu thuế trong quá trình thu hút FDI tại sáu nước đang phát triển trong khối ASEAN (Campuchia, Indonesia, Malaysia, Philippines, Thái Lan và Việt Nam) giai đoạn 2000 - 2017. Việc xem xét tác động của chính sách thuế thông qua các biến thuế thu nhập và thuế tiêu dùng, tổng số thu thuế đến FDI bằng phương pháp ước lượng POLS, FEM, REM và GLS. Kết quả thực nghiệm cho thấy, tổng số thu thuế tác động tiêu cực đến FDI, thuế thu nhập và thuế tiêu dùng có tác động tích cực đến FDI. Trên cơ sở đó, nghiên cứu đưa ra một số gợi ý chính sách về thuế để thu hút FDI đối với nhóm các quốc gia này.

Tư khóa: Thuế, chính sách thuế, đầu tư trực tiếp nước ngoài.

\section{Giới thiệu}

Đầu tư trực tiếp nước ngoài (FDI) là một loại hình đầu tư quốc tế, là việc nhà đâu tư chuyển tiền và các nguôn lực cần thiết khác đến không gian kinh tế khác không thuộc quốc gia nhà đầu tư, trực tiếp tham gia tổ chức, quản lý, điêuu hành doanh nghiệp nhằm mục đích kiếm lời. Đầu tư trực tiếp nước ngoài (FDI) đã và đang tác động mạnh đến nền kinh tế thế giới trong nhiều năm qua và là một chủ đề quan trọng đối với các quốc gia đang phát triển lẫn phát triển.
Đối với các quốc gia ASEAN, FDI được xem là công cụ quan trọng trong thúc đẩy phát triển kinh tế (Wang, 2009); FDI có thể giúp họ vượt qua sự trì trệ trong phát triển kinh tế và giải quyết nạn đói nghèo (Brooks, Hasan, Lee, Son, \& Zhuang, 2010). Theo Bwalya (2006), FDI có thể hỗ trợ cho tăng trưởng kinh tế thông qua 3 kênh: (i) hỗ trợ vốn (không liên quan đến nợ nần) nhằm tài trợ đâu tư cho nước thu hút; (ii) nâng cao trình độ kỹ thuật của nước thu hút và (iii) chuyển giao công nghệ mới cho các doanh nghiệp trong các nước này. Vì 
vậy, các quốc gia, đặc biệt là các nước đang phát triển luôn luôn cố gắng điều chỉnh các chính sách và thể chế phù hợp để thu hút các dòng vốn FDI. Trong tất cả các nhóm yếu tố này, đều đề cập đến chính sách thuế. Chẳng hạn, chính sách thuế thu nhập trong nhóm khung chính sách, chính sách thuế xuất, nhập khẩu trong nhóm yếu tố kinh tế, những ưu đãi thuế và cải cách thuế trong nhóm yếu tố tạo điều kiện kinh doanh... Vì vậy, việc nghiên cứu tác động của thuế và chính sách thuế có ý nghĩa rất lớn trong quá trình thu hút FDI của các quốc gia ASEAN.

\section{Tổng quan lý thuyết và các nghiên cứu thực nghiệm về tác động của chính sách thuế đến FDI}

\subsection{Lý thuyết về FDI}

Đâuu tư trực tiếp nước ngoài là một hình thức đâu tư quốc tế trong đó nhà đầu tư một nước thực hiện hoạt động sản xuất kinh doanh ở một quốc gia khác nhằm tối đa hóa lợi nhuận bằng cách khai thác các lợi thế của quốc gia nơi doanh nghiệp FDI đặt trụ sở. Lý thuyết và nghiên cứu thực nghiệm khám phá các yếu tố giải thích lý do MNCs lựa chọn thực hiện FDI tại một quốc gia khác được phát triển từ những năm 1930.

Bốn lý thuyết về FDI có ảnh hưởng mạnh nhất là: Lý thuyết về lợi thế so sánh (The Ownership Advantage theory (Hymer, 1960); Lý thuyết chu kỳ sống của sản phẩm (the Product Life Cycle theory (Vernon, 1996); Lý thuyết quốc tế hóa (the Internalisation theory (Coase, 1937);
Lý thuyết chiết trung (the Eclectic theory (Dunning, 1993; Dunning J. H., 1980). Trong đó, lý thuyết chiết trung của Dunning được sử dụng rộng rãi nhất trong những nghiên cứu gần đây khi quá trình hội nhập kinh tế ngày càng diễn ra sâu sắc. Lý thuyết chiết trung hội tụ được các nguyên lý đã đề cập trước đó để giải thích sự dịch chuyển FDI vào một nền kinh tế.

Dưới góc độ vĩ mô, các học thuyết vê FDI đều cho rằng FDI là một hình thức đâu tư cố định của hoạt động kinh doanh quốc tế xuyên biên giới. Theo Quỹ Tiền tệ Quốc tế (IMF, 1993): "Đầu tư trực tiếp nước ngoài (FDI) là hoạt động đâu tư được thực hiện nhằm thiết lập các mối quan hệ kinh tế lâu dài với một doanh nghiệp hoạt động trên lãnh thổ của một nền kinh tế khác nền kinh tế nước chủ đâu tư, mục đích của chủ đâu tư là giành quyền quản lý thực sự doanh nghiệp”. Ngày nay, xu hướng toàn cầu hóa đã khiến dòng vốn đâu tư trực tiếp nước ngoài ngày càng trở nên phổ biến trên thế giới.

\section{Một số lý thuyết vĩ mô giải thích về FDI gồm:}

\section{Lý thuyết chênh lệch lợi nhuận cận biên:} Lý thuyết chênh lệch lợi nhuận cận biên cho rằng FDI chảy từ nước có lợi nhuận cận biên thấp đến nước có lợi nhuận cận biên cao (Mac Dougal-Kempt, 1960).

Lý thuyết tỷ giá hối đoái: Lý thuyết này được Aliber (1971) nêu ra, và được Froot và Stein (1991) phát triển thêm. Aliber cho rằng nguyên nhân của $\mathrm{FDI}$ là do sự khác biệt về giá trị của các đông tiền khác nhau. 
Các doanh nghiệp của những nước có đông tiên mạnh thường tiến hành đầu tư ra nước ngoài; còn những doanh nghiệp của nước có đông tiền yếu thì ít có khả năng đó. Lý thuyết này được hình thành trên cơ sở quan hệ giữa thị trường vốn, tình trạng ngoại tệ và các thị trường tài chính khác. Khi đông tiên tăng giá thì kéo theo xu hướng gia tăng FDI.

Lý thuyết kéo đẩy: Nguyên nhân tạo ra dòng chảy vốn FDI được quy thành 2 nhóm là nhóm các yếu tố đẩy (push factors) và nhóm các yếu tố kéo (pull factors). Các yếu tố đẩy gồm các yếu tố thuộc về lợi thế so sánh của chủ đầu tư, của nền kinh tế có vốn đâu tư và của môi trường đầu tử toàn cầu. Các yếu tố kéo gồm các yếu tố có lợi thế so sánh của nước nhận đâu tử. Từ lý thuyết này có thể rút ra ý nghĩa cho các quốc gia muốn thu hút FDI cân duy trì và phát triển các yếu tố kéo của quốc gia mình. Do đó, việc đánh giá môi trường đầu tư để đưa ra giải pháp cải thiện môi trường đầu tư là việc làm cân thiết, thường xuyên và cân được quan tâm để thu hút nhiêu hơn FDI.

Kể từ đầu những năm 1980, các nghiên cứu thực nghiệm phong phú đã phân tích các chính sách nhằm thu hút FDI với sự tập trung đặc biệt vào tác động của các chính sách thuế, đặc biệt thuế đối với doanh nghiệp FDI.

\subsection{Chính sách thuế đối với FDI}

Một nghiên cứu của IMF đã kết luận có bằng chứng rõ ràng rằng chính sách thuế có tác động tới các luông vốn đầu tư nước ngoài, đặc biệt là nguôn vốn đầu tư trực tiếp. Nghiên cứu đã chỉ ra trong số các nước được quan sát, những nước có mức thuế thấp hơn thu hút được nhiều FDI hơn các nước có mức thuế cao hơn. Chẳng hạn, trong giai đoạn 1996 - 2000, bốn nước châu Âu là Ireland, Hà Lan, Lucxambua và Thụy Sĩ, mặc dù chỉ chiếm 9\% GDP của châu Âu nhưng lại thu hút được tới 38\% FDI của Mỹ vào châu Âu do những nước này áp dụng mức thuế suất thấp hơn. Tương tự như vậy, một nghiên cứu gần đây của James Hines - Đại học Michigan kết luận rằng “Đã có những bằng chứng xác thực chỉ ra sự tác động đáng kể của chính sách thuế trong việc thu hút vốn đâu tư trực tiếp nước ngoài, vay nợ của các doanh nghiệp, giá cả chuyển giao, chi trả cổ tức, bản quyền, các hoạt động nghiên cứu và phát triển". Hiện tượng này đã đặt Chính phủ các nước trên thế giới vào một sức ép mới - đó là sức ép cạnh tranh thuế toàn câu.

Có nhiều cách hiểu khác nhau về cạnh tranh thuế để thu hút FDI. Tuy nhiên, một cách hiểu chung nhất đó là việc một nước ban hành chính sách thuế có lợi thế so sánh nhằm thu hút nguôn lực, lao động và các yếu tố kinh tế khác tù bên ngoài vào nước minh, hoặc (đông thời) để hạn chế sư di chuyên các nguôn lực tù trong nước ra nước ngoài. Cạnh tranh thuế có thể được thựic hiện dưới hai hình thức cơ bản. Một là, thiết lập các chính sách nhằm thu hút việc đặt địa điểm thực tế diễn ra các hoạt động kinh tế của các công ty nước ngoài; Hai là, thiết lập các chính sách nhằm thu hút địa điểm cư trú của công ty. Cả hai hình thức này đều 
có thể được thực hiện bằng cách ban hành mức thuế suất thấp hơn những nước khác nhằm tạo ra những "nơi ẩn thuế", hoặc áp dụng cùng mức thuế suất với các nước khác nhưng sử dụng nhiều hình thức ưu đãi như miễn thuế, giảm thuế, hoặc các biện pháp ưu đãi khác để thu hút các nguôn đầu tư nước ngoài.

Tuy nhiên, xét cả về mặt lý luận và thực tiễn, cạnh tranh thuế toàn câu có thể tạo ra cả lợi thế và thách thức đối với mỗi nước. Vấn đề là mỗi quốc gia cần có những đối sách thích hợp nhằm phát huy tối đa những lợi thế và hạn chế những hệ quả phát sinh từ quá trình này nhằm phục vụ tốt nhất cho đường lối phát triển của mình.

Xét trên khía cạnh tích cực, cạnh tranh thuế toàn câuu có thể mang đến những mặt lợi sau đây: Thứ nhất, việc cắt giảm thuế suất và cung cấp các biện pháp khuyến khích thông qua ưu đãi, miễn, giảm thuế là tín hiệu tốt của nước chủ nhà đối với các luôn vốn đầu tư nước ngoài. Thứ hai, cạnh tranh thuế làm cho các Chính phủ mất thế độc quyền và phải quan tâm nhiều hơn đến chính sách, thông lệ quốc tế. Thứ ba, thuế suất thấp sẽ làm giảm gánh nặng phụ trội do thuế gây ra. Thuế suất được giảm nhẹ sẽ khuyến khích các doanh nghiệp và cá nhân tự nguyện chấp hành, tuân thủ các quy định của luật thuế mà không cần phải tìm mọi biện pháp trốn thuế, hoặc tránh thuế.

Bên cạnh những khía cạnh tích cực, cạnh tranh thuế toàn cầu cũng đặt ra những thách thức lớn đối với Chính phủ của các nước. Cạnh tranh thuế thông qua việc cắt giảm thuế suất và tăng cường áp dụng các ưu đãi thuế diễn ra đông loạt ở các nước là nguy cơ thu hẹp cơ sở đánh thuế của mỗi nước và do đó làm hạn hẹp nguôn thu của Chính phủ.

\subsection{Nghiên cứu thực nghiệm tác động của chính sách thuế đến FDI}

\subsubsection{Tác động của thuế thu nhập đến FDI}

Devereux (1995) đã phân tích cho thấy gánh nặng thuế theo từng quốc gia cụ thể đối với đầu tư xuyên quốc gia. Mẫu của nghiên cứu bao gồm 7 nước OECD trong giai đoạn 1985 - 1989. Nghiên cứu kết luận rằng sự lựa chọn vị trí đầu tư FDI thực sự bị ảnh hưởng bởi thuế thu nhập. Cụ thể, việc cung cấp các khoản tín dụng về thuế sẽ làm tăng vốn FDI cho các quốc gia.

Tiếp theo, trên cơ sở kết quả nghiên cứu của Lansbury (1996) và (Holland, 1998) về các yếu tố truyền thống, Carstensen (2004) đã sử dụng mô hình moment tổng quát (GMM) để xác định các yếu tố khuyến khích và cản trở vốn đâu tư nước ngoài từ các nước $\mathrm{OECD}$ vào 7 quốc gia chuyển đổi ở Trung và Đông Âu trong giai đoạn 1993 - 1999. Trong số các biến truyền thống, kết quả phân tích cho thấy thị trường tiềm năng, lợi thế so sánh trong đó có: thuế suất thuế doanh nghiệp thấp, chi phí lao động thấp, và các nguôn lực khai thác có tác động đến vốn đầu tư nước ngoài.

Nghiên cứu các nước châu Á, Wei (1997), đã nghiên cứu ảnh hưởng của thuế và tham 
nhũng đến đâu tư trực tiếp quốc tế từ mười bốn quốc gia nguôn tới 45 nước chủ nhà. Tác giả sử dụng dữ liệu vĩ mô của 14 quốc gia OECD (gồm châu Á và châu Mỹ). Kết quả cho thấy, nếu mức độ tham nhũng gia tăng 1 điểm, tỷ lệ thuế của các công ty đa quốc gia tăng tương ứng 7,5 điểm, và khi đó sẽ giảm đầu tử trực tiếp nước ngoài đối với các quốc gia từ Siangapor đến Mexico trong dữ liệu nghiên cứu.

Buettner (2002) trong nghiên cứu của mình, đã sử dụng chi phí vốn song phương trong khi hâuu hết các tác giả khác nghiên cứu FDI dựa vào ảnh hưởng của các biện pháp thuế đơn phương. Dựa vào mẫu dữ liệu của khối EU từ năm 1991 đến năm 1998, ông cho rằng gánh nặng thuế cận biên (EMTR) và thuế suất theo luật định (STR), thuế suất trung bình hiệu quả (EATR) đã gây ảnh hưởng trong việc xác định FDI.

Razin (2005) nghiên cứu dũ̃ liệu FDI kinh tế vĩ mô song phương. Họ phân tích dữ liệu bảng song phương với 24 nước OECD trong giai đoạn 1981 đến 1998 và giải quyết vấn đề lựa chọn mẫu cơ bản bằng phương pháp lựa chọn Heckman. Kết quả của họ cho thấy rằng thuế suất theo luật định quốc gia nguồn là một yếu tố quan trọng trong quá trình lựa chọn FDI, trong khi thuế suất nước chủ nhà ảnh hưởng đến quy mô đầu tư.

Bénassy-Quéré (2005) nghiên cứu FDI song phương trên 11 quốc gia $\mathrm{OECD}$ trong giai đoạn 1984 - 2000, cho thấy thuế doanh nghiệp tương đối cao sẽ không khuyến khích dòng vốn FDI, ngay cả khi các yếu tố trọng lực và việc cung cấp hàng hóa công cộng được kiểm soát. Do đó, mặc dù tiềm năng thị trường không quan trọng, chênh lệch thuế doanh nghiệp cũng đóng một vai trò quan trọng trong việc thúc đẩy dòng vốn FDI.

Demekas (2007) nghiên cứu ảnh hưởng của thuế đến FDI của 16 quốc gia và 24 nước Trung và Đông Âu CEEC trong giai đoạn 1995 - 2003 thông qua thuế suất thuế thu nhập doanh nghiệp theo luật định. Dựa trên bộ dữ liệu này, họ kết luận rằng ảnh hưởng của thuế đến FDI là đáng kể, nếu thuế suất luật định tăng $1 \%$ thì dòng vốn FDI giảm 2\%.

Wijeweera \& ctg. (2007) sử dụng dữ liệu bảng của OECD từ 9 quốc gia đầu tư vào Hoa Kỳ trong khoảng thời gian từ năm 1982 đến năm 2000. Trong ước lượng hôii quy, họ sử dụng biến kiểm soát khác nhau về thuế, gồm thuế cận biên cũng như thuế suất theo luật định. Kết quả là thuế suất theo luật định ảnh hưởng đến FDI mạnh mẽ hơn đối với biện pháp thuế hiệu quả.

Nghiên cứu tại Việt Nam, Cao Thị Hông Vinh (2017) (2013) nghiên cứu tác động của việc gia nhập WTO đến dòng vốn FDI vào Việt Nam. Áp dụng phương pháp FE, RE với dữ liệu bảng giai đoạn 1995-2011. Tác giả cho thấy tác động rõ rệt của việc tham gia WTO tới dòng vốn FDI vào Việt Nam. Bên cạnh đó, còn cho thấy cuộc khủng hoảng ngân hàng năm 1997 làm gia tăng dòng vốn FDI vào Việt Nam, các hiệp định song phương cũng giúp thu hút dòng FDI 
nhiêu hơn, cơ sở hạ tầng (đo lường bằng tỷ lệ người sử dụng điện thoại và internet) có tác động cùng chiều với FDI, việc giảm thuế suất của Việt Nam cũng giúp thu hút FDI nhiêu hơn và các nhà đầu tư còn quan tâm đến thể chế, ổn định chính trị, kiểm soát tham nhũng.

Đặng Văn Cường (2018) đã đánh giá tác động của gánh nặng thuế (GNT) và tham nhũng đến đầu tư trực tiếp nước ngoài (FDI) tại sáu nước đang phát triển trong khối ASEAN (Campuchia, Indonesia, Malaysia, Philippines, Thái Lan và Việt Nam) giai đoạn 1996 - 2014. Bằng việc sử dụng các phương pháp ước lượng GLS, 2SLS và GMM đối với dữ liệu bảng, kết quả thực nghiệm cho thấy, gánh nặng thuế có tác động nghịch chiều đến FDI, trong khi tham nhũng lại có tác động cùng chiều.

\subsubsection{Tác động của thuế tiêu dùng đến FDI}

Brander (1987) cho rằng các nước chủ nhà có thể thu hút FDI bằng cách áp thuế quan đối với hàng nhập khẩu và làm giảm thuế đối với sản xuất trong nước.

Desai (2005), đã xem xét tác động của các khoản thuế gián tiếp (phi thu nhập) đối với FDI của các công ty đa quốc gia Hoa Kỳ. Tác giả cho rằng Chính phủ áp đặt nhiêu loại thuế cho nhà đâu tư nước ngoài gồm cả thuế trực thu và gián thu, mặc dù các nghiên cứu về ảnh hưởng của chính sách thuế về vị trí đầu tư trực tiếp nước ngoài (FDI) tập trung hầu hết vào thuế thu nhập doanh nghiệp. Do đó, tác giả sử dụng mô hình Fixed effects, OLS với các biến là thuế trực thu và gián thu để cho thấy tác động của thuế gián thu đến FDI. Kết quả cho thấy Thuế suất thuế thu nhập doanh nghiệp cao làm giảm tỷ lệ vốn/lao động và tỷ suất lợi nhuận của các FDI, trong khi thuế suất gián tiếp cao thì không và đề xuất các cơ chế mà thuế trực tiếp và gián tiếp ảnh hưởng đến FDI đối với Chính phủ.

Aqeel (2004) xác định bằng thực nghiệm các nhân tố quyết định nguồn vốn FDI ở Pakistan trong giai đoạn 1961 - 2003. Thông qua kiểm định đông liên kết và mô hình hiệu chỉnh sai số, kết quả nghiên cứu cho thấy quy mô thị trường, thuế xuất nhập khẩu, tỷ giá hối đoái, thuế suất, tín dụng dành cho khu vực tư nhân là những nhân tố quyết định có ý nghĩa của FDI.

Nistor (2013) nghiên cứu về tác động của thuế đến FDI trường hợp của quốc gia Rumani. Tác giả muốn xem xét trong trường hợp sự phát triển kinh tế của một quốc gia đại diện cho tiêu dùng (được tính bằng thu nhập VAT cho quốc gia) và sản xuất (được đo bằng sự thay đổi trong thuế thu nhập doanh nghiệp) sẽ tạo ra tăng đâu tư trực tiếp nước ngoài. Nghiên cứu đã sử dụng dữ liệu thống kê số liệu của Romania, và thực hiện một loạt các mô hình hồi quy xem FDI có bị ảnh hưởng bởi thuế thu nhập doanh nghiệp và thuế giá trị gia tăng. Do đó, tác giả tập trung vào mối liên hệ giữa thuế và đầu tư trực tiếp nước ngoài và cuộc đấu tranh của Chính phủ để tạo ra một chế độ thuế thu hút các nhà đầu tư và mặt khác tăng doanh thu thuế. Kết quả là trong trường hợp của Romania, sự bùng nổ kinh tế giai 
đoạn 2004 - 2008, khi sản phẩm trong nước tăng đáng kể, đã thu hút rất nhiêuu công ty nước ngoài tham gia vào thị trường mới nổi của Đông Âu. Tất nhiên phát triển kinh tế không phải là lời giải thích duy nhất cho sự gia tăng FDI, nhưng cũng có thể được giải thích bởi các chi phí của Rumani như yếu tố thị trường, giá sản xuất, giá lao động và giá vận chuyển,...

\subsubsection{Nghiên cứu thực nghiệm chính sách thuế không làm tăng FDI}

Easson (2002) kết luận rằng kiến thức phổ biến rằng các ưu đãi thuế đối với FDI là không hợp lý về lý thuyết và thực tế. Về mặt lý thuyết họ thấy uuu đãi thuế tiêu cực vì họ bóp méo quyết định đâu tư. Trên thực tế, các ưu đãi về thuế được coi là không hiệu quả và dễ bị tham nhũng, do đó kết luận rằng chúng là tiêu cực (Easson, 2002). Tuy nhiên, hâu hết tất cả các quốc gia tiếp tục sử dụng chúng vì một số lý do, trong đó chủ yếu là ưu đãi thuế.

Một số lý thuyết khác nghiên cứu ở lĩnh vực kinh tế công nhấn mạnh những điều kiện số lượng lớn và không đồng nhất về cạnh tranh thuế như là sự tác hại và tập hợp thuế thì mang lại lợi ích hơn, chẳng hạn: Bird, (1993) cho rằng: Ưu đãi thuế chỉ cải thiện hiệu quả kinh tế nếu các quan chức Chính phủ có khả năng quyết định các loại hình và phương tiện sản xuất tốt nhất cho một nên kinh tế tốt hơn nhà đâu tư tư nhân.

Wilson (1999), Feld (2011) và Fuest (2009) nghiên cứu thực nghiệm về cạnh tranh thuế có sự tăng mạnh trong những năm gần đây, và tập trung vào để xem xét ảnh hưởng của thuế đối với dòng vốn đâu tư nước ngoài.

Bên cạnh đó, một số các nghiên cứu cho rằng chính sách thuế thu nhập chưa tác động cụ thể đến dòng FDI của các quốc gia. Chẳng hạn như:

Slemrod (1990) đã xem xét lại các nghiên cứu đã thực hiện, và phân tích riêng FDI song phương của Mỹ từ bảy quốc gia khác nhau về chế độ giảm thuế kép, Slemrod không đưa ra những kết luận rõ ràng vê ảnh hưởng của thuế quốc gia đối với dòng vốn FDI. Kết quả của (Wolff, 2007), (Razin A. Y., 2005) theo cách tiếp cận thực nghiệm cũng cho rằng thuế không tác động mạnh mẽ đến FDI. Tác giả sử dụng một dữ liệu bảng các dòng FDI song phương cho 27 quốc gia EU (ngoại trừ Rumani) trong giai đoạn 1994 - 2003 và chạy hồi quy cho tổng FDI cũng như vốn FDI, các giao dịch nợ giữa các công ty và lợi nhuận giữ lại. Kết quả của ông là hỗn hợp. Ảnh hưởng của thuế đối với tổng vốn FDI và vốn chủ sở hữu không có tác động đáng kể.

Có thể thấy, hầu hết các nghiên cứu mà tác giả thống kê đều kết luận tác động của chính sách thuế đối với FDI. Tuy nhiên, mức độ tác động của thuế là khác nhau, phụ thuộc vào nguôn dũ̃ liệu, phương pháp nghiên cứu, và cả đặc điểm của quốc gia, hoặc nhóm quốc gia mà các tác giả nghiên cứu. Kết quả nghiên cứu phần lớn thuế thu nhập có tác động mạnh mẽ đến dòng FDI, một số nghiên cứu chỉ cho rằng tác động 
đến một số ngành nghề của FDI, thậm chí có cả trường hợp kết luận ảnh hưởng của thuế đến FDI là không đáng kể.

\section{Phương pháp nghiên cứu}

\subsection{Mô hình và mô tả các biến}

Bài nghiên cứu tiến hành đánh giá tác động của chính sách thuế, gồm biến thuế thu nhập, thuế tiêu dùng, tổng số thu thuế và chỉ số giờ nộp thuế đến đâu tư trực tiếp nước ngoài của các quốc gia ASEAN trong giai đoạn từ năm 2000 đến 2017. Mô hình nghiên cứu được xây dựng dựa trên việc kế thừa các nghiên cứu trước đây, đặc biệt là mô hình của Shang-Jin, Wei. (1997), và Loan-Alin Nistor, Dragoș Păun (2013). Từ đó mô hình được sử dụng như sau:

$$
\operatorname{LogFDI}_{i t}=\beta_{0}+\beta_{1} \mathrm{TTN}_{\mathrm{it}}+\beta_{2} \mathrm{TGT}_{\mathrm{it}}+\beta_{3} \mathrm{TAX}_{\mathrm{it}}+\beta_{4} \mathrm{TIM}_{\mathrm{it}}+\beta_{5} \mathrm{COR}_{\mathrm{it}}+\varepsilon_{\mathrm{it}}
$$

\section{Trong đó:}

$\mathrm{i}=1,2,3, \ldots, \mathrm{N}$ và $\mathrm{t}=1,2,3, \ldots, \mathrm{T}(\mathrm{N}$ và $\mathrm{T}$ lần lượt là số quốc gia và khoảng thời gian quan sát trong mô hình);

$\operatorname{LogFDI}_{\text {it: }}$ Biến phụ thuộc, là Logarit của vốn FDI tiếp nhận ròng hàng năm.

$\mathbf{T T N}_{\mathrm{it}}$ : Biến thuế thu nhập, đây là số thuế tính trên thu nhập và lợi nhuận giữ lại, được tính là tỷ lệ \% trên tổng số thu thuế. Nghiên cứu của (Wei S. J., 2000), (Bellak, 2007)cho rằng, các doanh nghiệp FDI thường chỉ quan tâm đến thuế thu nhập doanh nghiệp - thuế suất của thuế thu nhập doanh nghiệp tác động trực tiếp đến lợi nhuận sau thuế mà nhà đầu tư nhận được tại nước sở tại.

TGT $_{\text {it }}$ Biến thuế tiêu dùng, là thuế hàng hóa và dịch vụ, là số thuế tính trên HHDV của lĩnh vực công nghiệp và dịch vụ, là tỷ lệ \% trên giá trị của HHDV. Nghiên cứu của (Nistor, 2013) sử dụng biến thuế GTGT (VAT) để đo lường tác động của thuế gián thu đối với FDI trong trường hợp của Romania. Tuy nhiên, dữ liệu của các nước
ASEAN còn hạn chế, vì vậy tác giả sử dụng các loại thuế biến đổi đối với hàng hóa và dịch vụ (\% giá trị gia tăng của ngành công nghiệp và dịch vụ). Theo $\mathrm{WB}$, thuế đánh vào hàng hóa và dịch vụ bao gồm thuế giá trị gia tăng, thuế tiêu thụ chọn lọc đối với dịch vụ, thuế sử dụng hàng hóa hoặc tài sản, thuế khai thác và sản xuất khoáng sản và lợi nhuận của các độc quyền tài chính. Vì vậy, nghiên cứu sử dụng các loại thuế biến đổi đối với hàng hóa và dịch vụ (\% giá trị gia tăng của ngành và dịch vụ) để đo lường.

$\mathbf{T A X}_{\mathrm{it}}$ : biến số thu thuế theo \% GDP. Theo WB, tỷ lệ số thu thuế \% GDP bao gồm tất cả các khoản thu nộp cho ngân sách (gồm thuế, phí, bảo hiểm,...). Do đó, nhiều nghiên cứu sử dụng biến TAX đại diện cho gánh nặng thuế của FDI do hạn chế về dữ liệu nhiên cứu. Chẳng hạn, Messere \& Owens (1987), OECD (2000), Burn (2004), Kiss (2009) sử dụng chỉ tiêu doanh thu thuế trên GDP để đại diện cho biến số thu thuế (gánh nặng thuế). Tương tự, Đặng Văn Cường (2018) cũng sử dụng biến TAX để đại diện cho 
gánh nặng thuế trong nghiên cứu về FDI của các quốc gia Asean.

TIM $_{\mathrm{it}}$ : Chỉ số giờ nộp thuế (Đo lường bằng thời gian - số giờ chuẩn bị hô sơ thuế và thời gian nộp thuế, theo $\mathrm{WB}$ ). Đây là biến độc lập tác giả sử dụng khác với các mô hình của những tác giả trước, do sự hạn chế về số liệu, tác giả đo lường chính sách thuế bằng chỉ số giờ nộp thuế (bên cạnh các biến độc lập được sử dụng nhiêu trong các nghiên cứu trước như: số thu thuế TNDN, GTGT,...). Hầu hết các nghiên cứu trước, không đề cập đến biến TIM do Chỉ số giờ nộp thuế được WB thống kê từ sau năm 2000.

$\mathrm{COR}_{\mathrm{it}}$ : Chỉ số kiểm soát tham nhũng (theo WB) thể hiện sự minh bạch, trách nhiệm và tham nhũng trong khu vực công, được đo lường theo thang điểm từ 1 đến 6 , trong đó quốc gia có điểm càng nhỏ thì kiểm soát tham nhũng càng cao (ít tham nhũng).

$\varepsilon_{\mathrm{it}}-$ phần dư của mô hình với $\varepsilon i t ~ \approx$ i.i.d $(0, \sigma \mathrm{i} 2), \mathrm{E}(\mu \mathrm{i} / \varepsilon \mathrm{it})=0$;

So với mô hình các yếu tố tác động đến FDI của Shang-Jin, Wei. (1997), và LoanAlin Nistor, Dragoș Păun (2013), tác giả đã đưa vào mô hình các biến giải thích về thuế và chính sách thuế bao gồm thuế thu nhập, thuế tiêu dùng và chỉ số giờ nộp thuế, trong khi các tác giả trước chỉ tập trung vào biến thuế suất thuế TNDN.

Bảng 1. Đo lường các biến và nguồn dữ liệu

\begin{tabular}{|l|l|l|l|}
\hline \multicolumn{2}{|c|}{ Biến } & \multicolumn{1}{c|}{ Đo lường } & Dũ liệu \\
\hline Biến phụ thuộc & LogFDI & Logarit của vốn FDI tiếp nhận ròng hàng năm & World Bank \\
\hline \multirow{4}{*}{ Biến độc lập } & TTN & Thuế thu nhập (\% lợi nhuận) & World Bank \\
\cline { 2 - 4 } & TGT & Thuế tiêu dùng (\% hàng hóa, dịch vụ) & World Bank \\
\cline { 2 - 4 } & TAX & Tổng số thu thuế (\% GDP) & World Bank \\
\cline { 2 - 4 } & TIM & Chỉ số giờ nộp thuế (số giờ) & World Bank \\
\cline { 2 - 4 } & COR & Chỉ số kiểm soát tham nhũng & World Bank \\
\hline
\end{tabular}

Nguôn: Tác giả tổng hợp

Dũ liệu được thu thập từ sáu quốc gia khu vực ASEAN là Campuchia, Indonesia, Malaysia, Philippines, Thái Lan và Việt Nam trong giai đoạn 2000 - 2017. Dữ liệu của các quốc gia Đông Timor, Lào, Myanmar không thu thập được và Singapore có sự chênh lệch quá lớn về trình độ phát triển so với các quốc gia còn lại.

\subsection{Phương pháp nghiên cứu định lượng}

Để phân tích tác động của chính sách thuế đến vốn FDI tại các nước ASEAN, bài viết sử dụng các phương pháp ước lượng bằng các phương pháp POLS, FEM, REM đông thời thực hiện các kiểm định (test) để lựa chọn phương pháp cho kết quả tối ưu. Tỷ lệ VIF đêu nhỏ hơn 10, nên mô hình không 
tôn tại hiện tượng đa cộng tuyến. Các F test, LM test đều nhỏ hơn $5 \%$, có bằng chứng để bác bỏ các giả thuyết. Kiểm định Hausman cho kết quả $\mathrm{P}$-value $<0.05$ cho thấy mô hình FEM là tối ưu. Kết quả hôi quy của các mô hình POL, REM, FEM đều có hệ số R-square đạt khá, trong đó FEM (mô hình lựa chọn) có R-square là $67,91 \%$ giải thích khá tốt tác động của các biến trong mô hình đối với FDI.

Tuy nhiên, khi kiểm định các vấn đề của FEM (Bảng 2), cho thấy việc sử dụng dữ liệu bảng để phân tích các quốc gia có thể gặp phải sự hiện diện của hiệu ứng nhóm, dẫn tới vấn đề sai số trong các kết luận thống kê. Khi kiểm định các khuyết tật của mô hình FEM, nhận thấy có vi phạm hiện tượng phương sai thay đổi, và hiện tượng tương quan phần dư của các đơn vị chéo, nên tác giả xử lý khuyết tật bằng cách sử dụng hôi quy theo phương pháp GLS (Generalized Least Squares) để khắc phục phương sai thay đổi và tự tương quan nhằm đạt được tính hiệu quả cho mô hình. Do đó, nghiên cứu này tiến hành hồi quy bình phương tối thiểu tổng quát khả thi FGLS với lệnh xtgls, thêm lựa chọn panel (hetero) nhằm khắc phục hiện tượng phương sai sai số thay đổi trong mô hình.

Bảng 2. Các kiểm định sai phạm của mô hình FEM

\begin{tabular}{|l|c|c|}
\hline \multicolumn{1}{|c|}{ Kiểm định } & \multicolumn{2}{c|}{ Kết quả } \\
\hline $\begin{array}{l}\text { Hiện tượng tự tương quan: } \\
\text { Wooldridge Test }\end{array}$ & Prob>F $=0.2707$ & Không vi phạm \\
\hline $\begin{array}{l}\text { Phương sai thay đổi: } \\
\text { Modified Wald test }\end{array}$ & Prob $>$ chi2 $=0.0000$ & Có vi phạm \\
\hline $\begin{array}{l}\text { Tương quan phân dư của các đơn vị chéo: } \\
\text { Pesaran's Test }\end{array}$ & $\operatorname{Pr}=0.0009$ & Có vi phạm \\
\hline
\end{tabular}

Nguôn: Kết quả của nhóm nghiên cưu

\section{Kết quả và thảo luận}

\subsection{Kết quả thống kê dũ liệu nghiên cứu và ma trận tương quan}

Bảng 3 thể hiện kết quả mô tả giá trị trung bình của các biến. 
Bảng 3. Thống kê Mô tả các biến

\begin{tabular}{|l|c|r|r|r|r|}
\hline \multicolumn{1}{|c|}{ Biến } & Quan sát & Trung bình & Độ lệch chuẩn & \multicolumn{1}{c|}{ Nhỏ nhất } & \multicolumn{1}{c|}{ Lớn nhất } \\
\hline LOGFDI & 108 & 9.493101 & 0.610479 & 7.911587 & 10.40003 \\
\hline TTN & 108 & 33.69204 & 11.75793 & 5.662442 & 52.85811 \\
\hline TGT & 108 & 7.325005 & 3.070407 & 3.302134 & 15.51554 \\
\hline TAX & 108 & 14.18847 & 3.509624 & 7.537844 & 22.40083 \\
\hline TIM & 108 & 320.6491 & 276.8932 & 118 & 1050 \\
\hline INF & 108 & 43.56481 & 14.15949 & 15 & 70 \\
\hline COR & 108 & 26.4475 & 17.24834 & 1.421801 & 62.08531 \\
\hline
\end{tabular}

Nguôn: Kết quả của nhóm nghiên cưu

Kết quả thống kê mô tả các biến cho thấy:

- Biến FDI sau khi sử dụng hàm logarit có giá trị trung bình là 9,49. Dữ liệu cho thấy, Indonesia là quốc gia có mức độ thu hút vốn FDI lớn nhất trong mẫu với trên 20 tỷ USD/năm và Campuchia là quốc gia thu hút ít FDI nhất trong khu vực với giá trị khoảng 84 triệu USD/năm.

- Nhóm biến về thuế:

Tỷ lệ thuế thu nhập trên số thu thuế của nhóm nước nghiên cứu trung bình là $33,69 \%$. Trong đó, Campuchia và Thái Lan có tỷ lệ thấp hơn so với tỷ lệ trung bình, và Philippine, Malaysia cao hơn nhiêu so với tỷ lệ trung bình. Điều này có thể thấy được trong cuộc canh tranh giảm thuế thu nhập để thu hút FDI, một số quốc gia đã giảm tỷ trọng thuế thu nhập so với các nước khác, và Thái Lan, Campuchia là 2 điển hình trong cuộc cạnh tranh này.

Đối với thuế tiêu dùng, do FDI của các quốc gia chủ yếu được đâu tư vào lĩnh vực công nghiệp và dịch vụ, thuế hàng hóa và dịch vụ (tính trên giá trị HHDV của lĩnh vực công nghiệp và dịch vụ) của các quốc gia tương đối thấp, trung bình là $7,3 \%$, giao động từ $3,3 \%$ đến $15,5 \%$ và ít có biến động lớn trong thời gian nghiên cứu, vì đây là thuế gián thu tính vào giá bán của $\mathrm{HHDV}$ nên các quốc gia điều chỉnh rất ít trong các kế hoạch cải cách thuế của mình. Chẳng hạn, thuế suất GTGT của Việt Nam phổ thông là $10 \%$ được duy trì suốt khoảng thời gian từ năm 1999 đến nay.

Biến đại diện cho tổng số thuế (theo \% GDP) có giá trị trung bình là $13,9 \%$ so với GDP, trong đó cao nhất là Việt Nam và thấp nhất là Campuchia. Ngoài ra, kết quả thống kê cũng cho thấy, tổng số thuế không phải là yếu tố tạo nên rào cản lớn đối với dòng vốn FDI. Cụ thể, mặc dù tỷ lệ này tại Campuchia là thấp nhất trong khu vực nhưng FDI tại nước này cũng thấp. Trong khi đó, Việt Nam là nước có tỷ lệ doanh thu thuế hàng năm lớn nhất với hơn $20 \%$ so với GDP nhưng có FDI tương đối khá với trên 9 tỷ USD hàng năm. 
Chính sách thuế khi đo lường bằng chỉ số thời gian nộp thuế, cho thấy mức độ tạo thuận lợi của chính sách thuế cho nhà đâu tư, có giá trị trung bình là 320,6 giờ. Quốc gia có số giờ càng ít thể hiện chính sách thuế tạo điều kiện thuận lợi hơn so với quốc gia có chỉ số giờ nộp thuế cao hơn. Trong nhóm nghiên cứu, Malaysia là quốc gia có môi trường nộp thuế tốt nhất với chỉ số giờ thấp nhất (dưới 200 giờ), trong khi Việt Nam là quốc gia có chỉ số giờ cao nhất, trên 1.000 giờ (giai đoạn năm 2000 đến 2009), và dù nổ lực trong việc cắt giảm giờ nộp thuế để tạo thuận lợi cho môi trường đầu tư, hiện nay số giờ của Việt Nam cũng còn cao hơn mức trung bình (498 giờ).
Chỉ số tham nhũng là biến đại diện về môi trường cạnh tranh thuế: của chỉ số kiểm soát tham nhũng tại các quốc gia khảo sát là tương đối thấp trung bình là 26,4 trong đó cao nhất là Malaysia (kiểm soát tốt tham nhũng) và thấp nhất là Campuchia (kiểm soát kém tham nhũng). Điều này cho thấy, mức độ tham nhũng tại các quốc gia khảo sát khá phổ biến. Kết quả này cũng hoàn toàn phù hợp với báo cáo của WorldBank (2000) cho rằng, các quốc gia này là thiên đường của nạn tham nhũng (trừ Singapore không nằm trong mẫu khảo sát).

Bảng 4. Ma trân hệ số tương quan giữa các biến

\begin{tabular}{|c|c|c|c|c|c|}
\hline BIẾN & LOGFDI & TTN & TGT & TAX & TIM \\
\hline TTN & $0.5203^{*}$ & & & & \\
\hline TGT & 0.0863 & $-0.4258^{*}$ & & & \\
\hline TAX & $0.3750^{\star}$ & $0.4309^{*}$ & $0.5376^{*}$ & & \\
\hline TIM & 0.1160 & 0.0719 & $0.6308^{*}$ & $0.7735^{*}$ & \\
\hline COR & $0.4956^{*}$ & $0.7829^{*}$ & $-0.3984^{*}$ & $0.3099^{*}$ & -0.1084 \\
\hline
\end{tabular}

* Biêu thị múc ý nghĩa $1 \%$.

Nguôn: Kết quả của nhóm nghiên cứu

Bảng 4 cho thấy, dấu của các biến giải thích trong mô hình với nghĩa thống kê ở mức $1 \%$. Nhìn chung, tương quan giữa các biến là thấp (giá trị của hệ số tương quan $<0.8)$, và do vậy, loại bỏ khả năng đa cộng tuyến trong các phân tích hôi quy (Evans, 1996).

\subsection{Kết quả thực nghiệm tác động của chính sách thuế đối với FDI}


Bảng 5. Tác động của cạnh tranh thuế đối với FDI của các quốc gia Asean

\begin{tabular}{|c|c|c|c|c|}
\hline Biến & OLS & FEM & REM & FGLS \\
\hline TTN & $.05194918^{* * *}$ & $.03821445^{\star *}$ & $.05194918^{* \star *}$ & $.05194918^{* \star *}$ \\
\hline TGT & $20747099^{* * *}$ & $.13359061^{\star * *}$ & $.20747099^{* * *}$ & $.20747099^{* * *}$ \\
\hline TAX & $-.11833293^{* * *}$ & -0.03001583 & $-.11833293^{\star * *}$ & $-.11833293^{* * *}$ \\
\hline TIM & -0.00011429 & -0.00045418 & -0.00011429 & -0.00011429 \\
\hline COR & $.01179292^{\star * *}$ & $.03470075^{\star * *}$ & $.01179292^{\star * \star}$ & $.01179292^{\star * *}$ \\
\hline _cons & $7.6268169^{* * *}$ & $6.8807873^{* * *}$ & $7.6268169^{* \star \star}$ & $7.6268169^{* \star *}$ \\
\hline $\mathrm{N}$ & 108 & 108 & 108 & 108 \\
\hline Wald test & & 0.0000 & & \\
\hline Sargan test & & & & \\
\hline
\end{tabular}

Ghi chú: ${ }^{* * *},{ }^{* *},{ }^{*}$ có múc ý nghĩa thống kê lân lượt là 1\%, 5\% và $10 \%$.

Nguôn: Kết quả của nhóm nghiên cứu

\section{Kết quả từ Bảng 5 cho thấy:}

Thuế thu nhập TTN: kết quả nghiên cứu cho thấy, thuế thu nhập tác động cùng chiều đến FDI, điều này ngược lại với một số nghiên cứu của Shang-Jin, Wei. (1997), Demekas \& ctg. (2007) cho rằng thuế TNDN làm giảm FDI. Điều này được giải thích rằng các nước Asean đang chạy đua trong cuộc cạnh tranh đến đáy của thuế thu nhập nhằm thu hút đầu tư, nên thuế TNDN thật sự không còn là yếu tố tiêu cực của FDI. Điều này phù hợp với thực trạng các quốc gia trong dữ liệu nghiên cứu, đây là khoảng thời gian các quốc gia ASEAN thường áp dụng chính sách cạnh tranh thuế, ưu đãi thuế đối với các nhà đầu tư nước ngoài và do đó thuế thu nhập không còn là rào cản lớn đối với FDI.

Thuế tiêu dùng TGT: có hệ số hôi quy biến TGT mang dấu dương và có ý nghĩa thống kê trong tất cả các kết quả ước lượng. Điều này cho thấy, thuế gián thu có tác động tích cực đối với vốn FDI. Kết quả này cũng phù hợp với nghiên cứu của Desai, M.A., C.F. Foley và J.R. Hines (2004), cho trường hợp của Hoa Kỳ và Loan-Alin Nistor, Dragoș Păun (2013) cho trường hợp của Rumani.

\section{Tổng số thu thuế theo \% của GDP (biến} TAX): kết quả thống kê cho thấy đều có tác động tiêu cực đối với FDI (dấu âm). Điều này tương đông với nhiêu tác giả khi sử dụng biến TAX để đo lường tác động của gánh nặng thuế chung đối với $\mathrm{FDI}$, chẳng hạn Buettner (2002), Đặng Văn Cường (2018).

Về chỉ số giờ nộp thuế: hệ số hồi quy của biến TIM mang dấu âm, dù chưa có ý nghĩa thống kê trong mô hình. Tuy nhiên, khi sử dụng TIM là biến công cụ giải thích cho thuế 
thu nhập TTN, thì TIM có tác động tiêu cực đối với TTN, qua đó giải thích TIM có tác động tiêu cực trong việc thu hút FDI. Điều này hoàn toàn phù hợp với thống kê mô tả, và thực trạng về các thủ tục hành chính thuế của các quốc gia, thời gian để thực hiện các thủ tục hành chính càng nhiều sẽ làm nản lòng các nhà đầu tự.

Về môi trường đầu tư: Chỉ số tham nhũng COR mang dấu dương và có ý nghĩa thống kê. Điều này phù hợp với các nghiên cứu của Heckelman \& Powell (2010), Đặng Văn Cường (2/2018) cũng cho rằng tham nhũng tại các nước Đông Nam Á là chất bôi trơn bánh xe thương mại ở quốc gia có thể chế yếu kém.

\section{Kết luận và hàm ý chính sách}

Kết quả thực nghiệm cho thấy trong chính sách thuế, thuế thu nhập và thuế tiêu dùng tác động tích cực, trong khi tổng số thu thuế tác động tiêu cực đến FDI của các nước ASEAN. Có thể thấy trong nhiều năm qua, các nước đã sử dụng thuế như một công cụ để cạnh tranh thu hút đầu tư và thúc đẩy nên kinh tế nội địa. Một cách cạnh tranh được quan tâm đáng kể đó là sự ưu đãi về thuế, miễn, giảm thuế suất, cho phép đâu tư và miễn thuế nhập khẩu cho hàng hóa vốn là những dạng thông thường nhất của ưu đãi thuế, nên tổng số thu thuế thường giảm sẽ thu hút nhiêu FDI. Tuy nhiên, kết quả thực nghiệm của bài báo cho thấy thuế thu nhập, và cả thuế tiêu dùng đều tác động tích cực đến FDI, có thể là do các quốc gia ASEAN đã sử dụng rất nhiều chính sách ưu đãi, miễn giảm thuế, nên dù tỷ trọng thuế TNDN trên tổng thu thuế tăng, nhưng vẫn thu hút được FDI. Do đó, các quốc gia đang phát triển khu vực ASEAN nên hoàn thiện hệ thống thuế, đặc biệt các chính sách ưu đãi thuế thu nhập, vì ưu đãi thuế chắc chắn sẽ dẫn đến giảm thu ngân sách, và thay vào đó là những thuận lợi khác (như thể chế chính trị, thị trường,...). Hơn nữa, về cải cách thủ tục hành chính thuế: Kết quả thực nghiệm cho thấy thời gian nộp thuế có tác động tiêu cực đối với việc thu hút FDI. Điều này có ý nghĩa đặc biệt đối với các nước ASEAN đang trong quá trình cải cách thuế (như Việt Nam), nên các quốc gia phải đẩy mạnh cải cách thủ tục hành chính thuế để hướng đến một nên hành chính thuận lợi, minh bạch,... cho các nhà đâu tư.

\section{TÀI LIỆU THAM KHẢO}

Aliber, P.Z. (1971). The impact of external markets for national currencies on central bank reserves. The Economics of common currencies, 178-195. Routledge.

Aqeel, A. N. (2004). The determinants of foreign direct investment in Pakistan [with comments]. The Pakistan Development Review, 651-664.

Bellak, C. A. (2007). Some Further Evidence on the Role of Effective Corporate Income Taxes as Determinants of Foreign Direct Investment in Central and East European Countries, in: 
National Tax Association (ed.). Proceedings of the National Tax Association Conference 2006, Boston, 311-343.

Bénassy-Quéré, A. F.-R. (2005). How does FDI react to corporate taxation? International Tax and Public Finance, 12(5), 583-603.

Brander, J. A. (1987). Foreign direct investment with unemployment and endogenous taxes and tariffs. Journal of International Economics, 22(3-4), 257-279.

Brooks, D., Hasan, R., Lee, J.-W., Son, H., \& Zhuang, J. (2010). Closing development gaps: challenges and policy options. ADB Economics Working Paper Series 209, Manila: Asian Development Bank.

Buettner, T. (2002). The Impact of Taxes and Public Spending on the Location of FDI: Evidence from FDI-flows within Europe. ZEW Discussion Paper No. 02-17, Available at SSRN: https:// ssrn.com/abstract=335724 or http://dx.doi.org/10.2139/ssrn.335724

Bwalya, S. M. (2006). Foreign direct investment and technology spillovers: Evidence from panel data analysis of manufacturing firms in Zambia. Journal of development economics, 81(2), 514-526.

Cao Thị Hồng Vinh (2015). Tác động hai chiêu của vốn FDI và môi trường kinh doanh của Việt Nam. Kỷ yếu hội thảo quốc tế ICYREB 2015, Đại học Kinh tế quốc dân.

Carstensen, K. \&. (2004). Foreign direct investment in Central and Eastern European countries: A dynamic panel analysis. Journal of comparative economics, 32(1), 3-22.

Coase, R. H. (1937). The pig-cycle in Great Britain: An explanation. Economica, 4(13), 55-82.

Demekas, D. G. (2007). Foreign direct investment in European transition economies - The role of policies. Journal of comparative economics, 35(2), 369-386.

Desai, M. A. (2005). Foreign direct investment and the domestic capital stock. American Economic Review, 95(2), 33-38.

Devereux, M. A. (1995). The Impact of Tax on Foreign Direct Investment: Empirical Evidence and the Implications for Tax Integration Schemes. International Tax and Public Finance 2, 85-106.

Dunning, J. (1993). The prospects for foreign direct investment in eastern Europe in Artesen P., Rojec M. and Svetlicic M. (Eds) Foreign investment in Central and Eastern Europe. Macmillan, London. Ellingstadt M.(1997) The maquiladora syndrome: Central European prospects, Europe-Asia Studies, 49(1), 7-21.

Dunning, J. H. (1980). Toward an eclectic theory of international production: Some empirical tests. Journal of International Business Studies, 11(1), 9-31.

Đặng Văn Cường (2018). Tác động của gánh nặng thuế và tham nhũng đến FDI tại các nước ASEAN. Tạp chí công nghệ ngân hàng, tháng 1/2018.

Easson, A. \&. (2002). Tax incentives. World Bank Instutute. 
Feld, L. P. (2011). FDI and taxation: A meta-study. Journal of economic surveys, 25(2), 233-272.

Fuest, C. \&. (2009). Tax evasion, tax avoidance and tax expenditures in developing countries: A review of the literature. Report prepared for the UK Department for International Development (DFID), 44.

Holland, D. \&. (1998). The determinants and impact of foreign direct investment in the transition economies: a panel data analysis. In Convergence or divergence: aspirations and reality in central and eastern Europe and Russia. Proceedings $4^{\text {th }}$ Annual conference, Centre for Research into East European Business, University of Buckingham.

Hymer, S. (1960). The international operations of national firms: A study of foreign direct. MIT Press.

Lansbury, M. P. (1996). Foreign direct investment in Central Europe since 1990: An econometric study. National Institute Economic Review, 156(1), 104-114.

Nistor, I. A. (2013). Axation and its effect on foreign direct investments - The case of Romania. Nauki o Finansach, 3(16), 37-47.

Razin, A. R. (2005). Corporate taxation and bilateral FDI with threshold barriers (No. w11196). National Bureau of Economic Research.

Razin, A. Y. (2005). Corporate Taxation and Bilateral FDI with Thereshold Barriers. NBER Working Paper, No. 11196.

Slemrod, J. (1990). Tax Effects on Foreign Direct Investment in the U.S.: Evidence from a Cross Country Comparison, in: A. Razin and J. Slemrod (eds.). Taxation in the Global Economy, University of Chicago.

Vernon, R. (1996). International Investment and International Trade in the Product Cycle. The Quarterly Journal of Economics, 80(2), 190-207.

Wang, M. \&. (2009). Foreign direct investment and economic growth: The growth accounting perspective. Economic Inquiry, 47(4), 701-710.

Wei, S. J. (1997). Why is corruption so much more taxing than tax? Arbitrariness kills. NBER working paper, (w6255).

Wei, S. J. (2000). How taxing is corruption on international investors? Review of economics and statistics, 82(1), 1-11.

Wilson, J. (1999). Theories of Tax Competition. National Tax Journal, 52, 269-304.

Wolff, G. (2007). Foreign Direct Investment in the Enlarged EU: Do Taxes Matter and to What Extent? Open Economies Review, 18, 327-346. 